\title{
Difference of Intensity of Heart Sounds Expressed Numerically. Preliminary Report".
}

Magnoscopic Investigation and Report.

By

Akira Sato and Yadori Moriwaki.

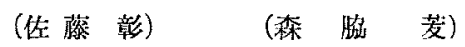

(From the Department of Pediatrics, Faculty of Medicine, the Tohoku Imperial University, Sendai.

Director: Prof. A. Sato.)

In the 1st Report') of the Magnoscopic Investigation, Nukiy a ma and Sato, one of us, described "micro rales", "latent bronchial breathing" and "latent bronchophonia", further "micro-friction" as new auscultatory phenomena. In the present paper we desire to express the difference of heart sounds numerically.

\section{Method used.}

Apparatus: the magnoscope and an attenuator connected to it. The pick-up of the magnoscope was applied over one of the two heart orifices to be compared with each other, and then over the other orifice. Then the pick-up was applied over the orifice of the louder sound and the dial switch of the attenuator was turned until the louder heart sound became almost equal to the lesser heart sound over the other orifice.

- Then the figures (=the number of decibels) were read and noted.

* Read at the General Meeting of the Japanese Pediatric Society, held at Niigata, April 1935.

1) A. S a to and H. Nukiy a ma, Tohoku J.'Exp. Med., 1940, 38, 45. 
